\title{
Automated calculation of the absorber temperature field of an inflatable collector
}

\author{
Olga Smirnova ${ }^{l}$, Yuri Avetisyan ${ }^{l}$, Nadezhda Dmitrienko ${ }^{1}$, and Oxana Balabaeva ${ }^{l}$ \\ ${ }^{1}$ Don state Technical University, 344000, Rostov-on-Don, Russian Federation
}

\begin{abstract}
This article deals with calculating temperature field of the inflatable collector made of polymer materials. The efficiency of the considered power system depends on the intensity of the absorber heating. In its turn, the process of heating coolant is affected by a great number of external environmental factors. The developed mathematical model and program product let the researchers consider various influence degree of each factor separately and in a complex.
\end{abstract}

\section{Introduction}

Using heat energy generated by alternative air power systems is in great demand in agriculture, tourism, drying operations of various production processes and house heating. The development of applied technologies in the chemical industry made it possible to develop and explore a new type of a collector- an inflatable one, made of polymer materials. Its effectiveness is largely determined by thermophysical properties of applied materials and accessories, constructive design, the quality of connecting details and the level of heat loss in energy transmission from the device to the heating object.

\section{Problem formulation}

To ensure maximum heat transfer from a useful area of the collector, a new design consisting of seriesconnected cylindrical segments is proposed in the article (Figure 1).

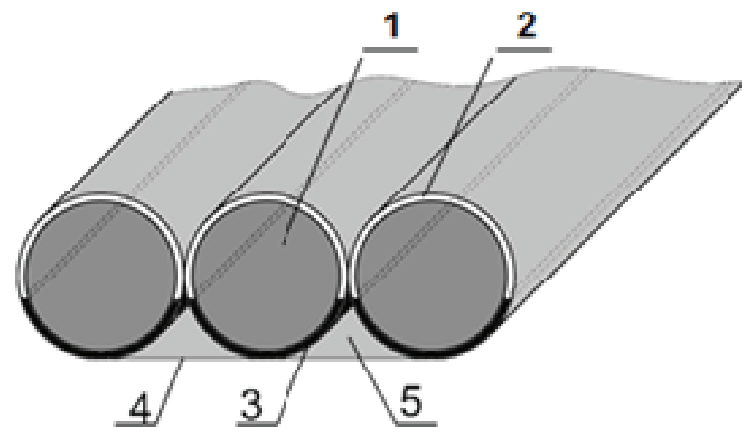

Fig. 1. An air inflatable collector in section 1 - a cylindrical segment of a collector; 2 - light-transmitting transparent layer of a segment; 3 - heat-absorptive layer of a segment (absorber); 4 - heat-insulation layer; 5 - coolant area.
Segments of the collector are made of two halfcylinders: the upper is light-transmitting and the lower is heat-absorbing, i.e. the absorber. Form stability of cylindrical segments is provided by filling the inner space with air. The interval between the segments is designed to accommodate the coolant.

Effective maintenance of the inflatable collector is provided by thermo-physical characteristics of the applied materials. Due to high rates of heat resistance and light transmission $(0,85)$, the upper layer of the semi cylinder is supposed to be made of polyethylene terephthalate. The absorber is likely to be made of polymer material of black color to ensure high heat conductivity, heat capacity, and thermal conductivity. The authors propose to use polyethylene of high density for the production of the absorber [1-3].

The study of the collector is fulfilled with the help of natural and laboratory research and let the authors determine a lot of factors influencing the intensity of the absorber heating[4-8]. The main environment factors are known to be intensity of insolation, the direction of solar radiation effect, the power of heat flow, wind speed, air humidity, and others.

To determine the impact degree of each of them is hard due to large number of variables. To solve this problem is possible if to apeal to mathematical modeling. Developing the mathematical model, the authors used the method of finite elements. As a research object a single cylindrical segment was selected, and its estimated area is presented on a figure 2 .

Due to using a high light transmission material for upper semi cylinder in a mathematical modeling a mathematical admission was based on the fact that the upper layer does not influence distribution of the temperature field of the absorber [8-12].

\footnotetext{
*Olga Smirnova: smir_nova@,inbox.ru
} 


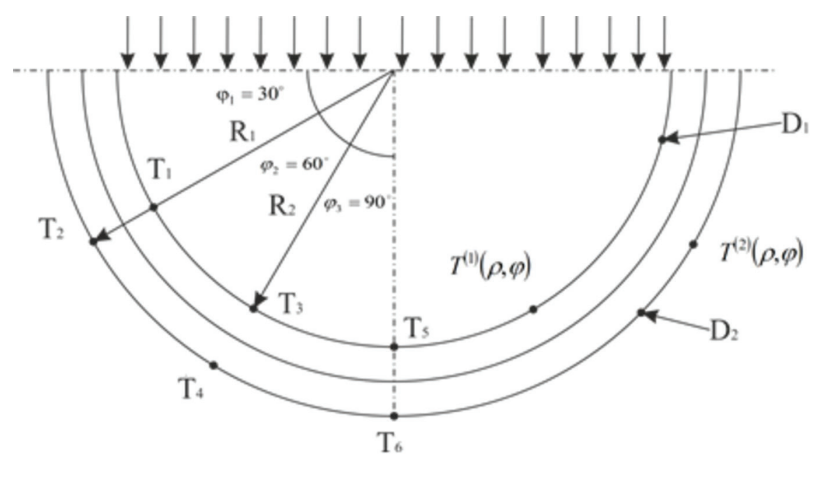

Fig. 2. An estimated area of the collector cylindrical segment

The basic data for mathematical simulation: air temperature Tat $=23^{\circ} \mathrm{C}$; heat flux, $q=q_{1} \sin \varphi$, $q_{1}=310 \mathrm{~W} / \mathrm{M} 2$; materials thermal conduction of the absorber: low layer $-\lambda_{1}=0,03 \mathrm{~W} / \mathrm{M} \cdot \mathrm{K} ; \quad$ upper layer $-\lambda_{2}=0,34 \mathrm{~W} / \mathrm{M} \cdot \mathrm{K} ;$ heat-transfer coefficient $\alpha_{T}=9,5 \mathrm{~W} / \mathrm{M} 2 \cdot \mathrm{K} ; \quad R_{1}=0,05 \mathrm{~m} ; \quad R_{2}=0,0492 \mathrm{~m} ;$ $\varphi_{1}=30^{\circ} ; \varphi_{2}=60^{\circ} ; \varphi_{3}=90^{\circ}$.
It is necessary to find distribution of temperature ranges in a set mode in the following points during mathematical simulation: $T_{1}\left(R_{1}, \varphi_{1}\right) ; \quad T_{2}\left(R_{3}, \varphi_{1}\right)$; $T_{3}\left(R_{1}, \varphi_{2}\right) ; T_{4}\left(R_{3}, \varphi_{2}\right) ; T_{5}\left(R_{1}, \varphi_{3}\right) ; T_{6}\left(R_{3}, \varphi_{3}\right)$.

The mathematical model of the task has the following form:

$$
\begin{array}{ll}
\text { area } D_{1} & \operatorname{div}\left(\lambda_{1} \operatorname{grad} T^{(1)}\right)=0 ; \\
\text { area } D_{2} \quad \operatorname{div}\left(\lambda_{2} \operatorname{grad} T^{(2)}\right)=0 .
\end{array}
$$

Consider the following boundary conditions: $\rho=R_{1}$,

$$
\begin{gathered}
\lambda_{2} \frac{\partial T^{(2)}}{\partial \rho}=-\alpha_{1}\left[T^{(2)}\left(R_{1}, \varphi\right)-T_{\text {oкp }}\right] ; \\
\rho=R_{2}, \\
T^{(1)}\left(R_{2}, \varphi, t\right)=T^{(2)}\left(R_{2}, \varphi, t\right) ; \lambda_{1} \frac{\partial T^{(1)}}{\partial \rho}=\lambda_{2} \frac{\partial T^{(2)}}{\partial \rho} .
\end{gathered}
$$

On the basis of this mathematical model a software product to facilitate and visualize the main mathematical calculations was developed. The interface of the program is given on the figure 3 .

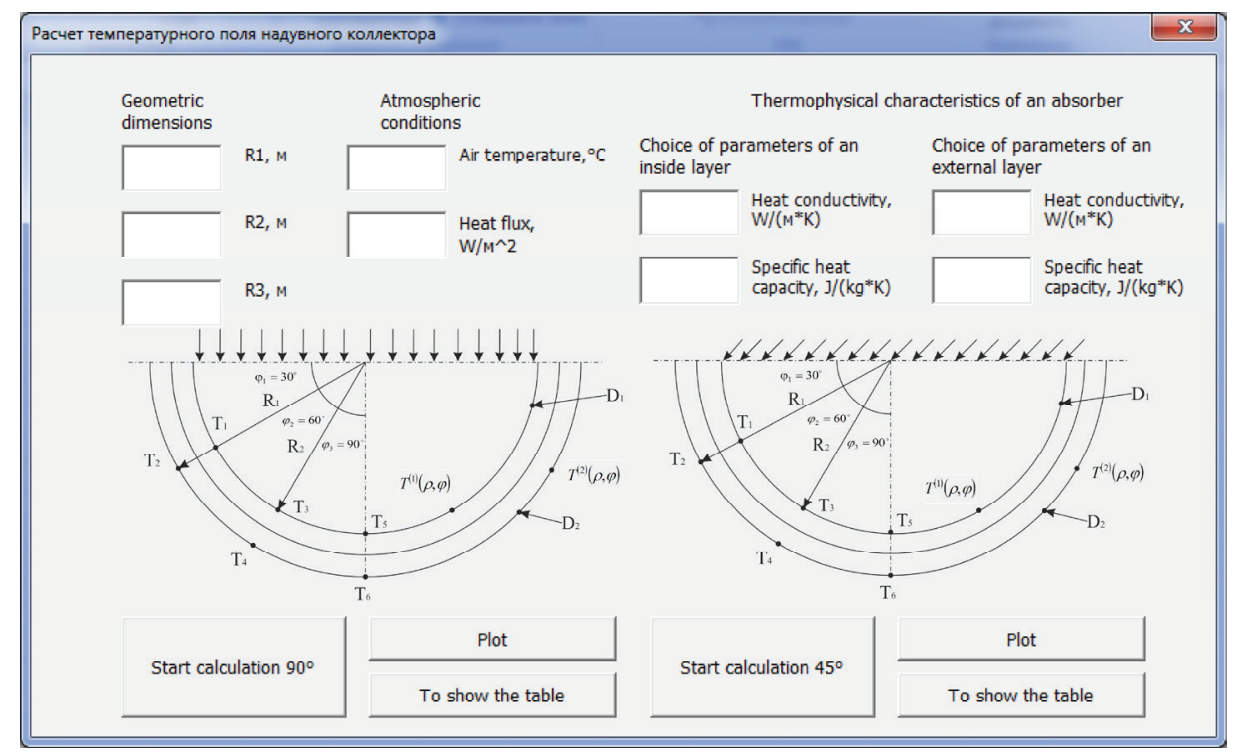

Fig. 3. Interface of the automated program calculation of the absorber temperature field of an inflatable collector

Varying the parameters of ambient temperature, changing thermal physical characteristics of applied materials [13, 14] and geometrical constructions of cylindrical segment of the collector, it is possible to calculate the distribution of the collector temperature field. The results of the calculations can be presented in the table or in the form of graphic dependences.

Let us consider the temperature distribution of the collector as it is supposed to be depend on the ambient air temperature and the heat flux maintenance intensity of the collector in different seasons. Constructive characteristics and properties of applied materials are left without changes.

Climate data [15], used in program calculation are given in the table 1 .
Table 1. Climatic parameters of the collector maintenance in various seasons

\begin{tabular}{|c|c|c|}
\hline Season & $\begin{array}{c}\text { Air temperature, }{ }^{\circ} \mathrm{C} \\
\text { (an average maximum } \\
\text { during the season) }\end{array}$ & $\begin{array}{c}\text { Heat flux, } W / \text { sq.m } \\
\text { (average monthly } \\
\text { values during } \\
\text { the season) }\end{array}$ \\
\hline Spring & 19,7 & 500 \\
\hline Summer & 35,4 & 623 \\
\hline Autumn & 18,09 & 353,3 \\
\hline
\end{tabular}

By means of using the program, temperature values of the absorber heating material were received on semi cylindrical surface at each $10^{\circ}$.

The diagrams of the absorber temperature distribution in three seasons of its maintenance are given 
in the figure 4. In the considered case, the light source is located at the right angle to diameter of the collector segment.

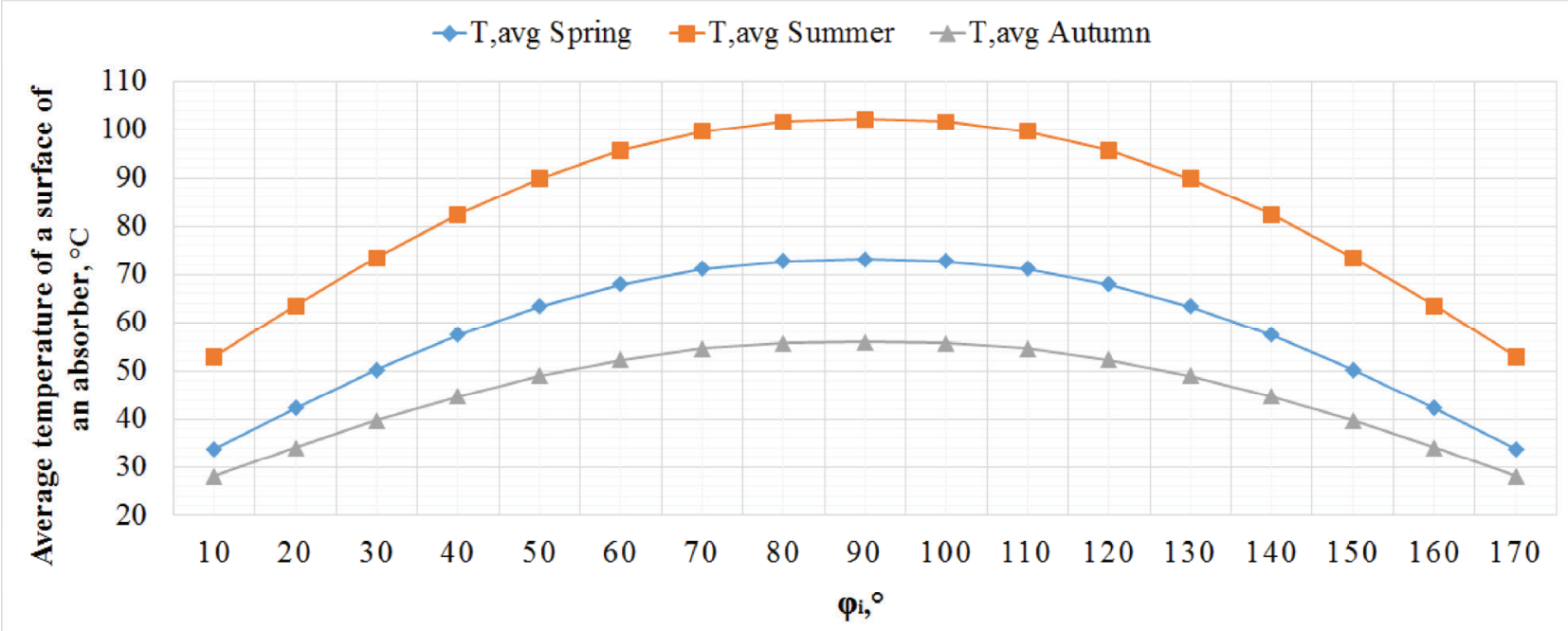

Fig. 4. The diagram of the absorber's average temperature distribution on a semi-cylindrical surface of a segment depending on error angle $\varphi$ in case of direct sunlight impact

It is necessary to point out that for the calculation various maximum parameter values of season maintenance are selected. It is natural that the maximum values of heating are stated during summer period as they are $102{ }^{\circ} \mathrm{C}$, more than $70{ }^{\circ} \mathrm{C}$ they reach in spring, and then they show significant decline in autumn to $20^{\circ} \mathrm{C}$ in comparison with spring temperature values. These temperature values are typically observed at noon under the influence of direct sun light, so it is necessary to guide or fix the collector to follow the sun position. As the considered collector design is characterized by low cost, high heating rates can be achieved due to the geometric structure design when using cylindrical segments in which the absorber is laid out in the form of a half-cylinder. Let us consider the distribution of the absorber temperature field under indirect effect of solar radiation. To meet this aim corresponding graphic dependencies were built by means of the above said software product.

In case of indirect influence of radiation, the distribution of the absorber temperature field has some specific features: higher temperature values are typical for lit quarter of a segment while lower values are typical for shadow side. In accordance to the figure 5 , the difference between shadow and lit absorber quarters laid out in the form of a semi cylinder with deviations from 15 to $23{ }^{\circ} \mathrm{C}$. At the same time, even minimum temperature values of the absorber, they are still higher than ambient air temperature values, at least, to $20^{\circ} \mathrm{C}$.

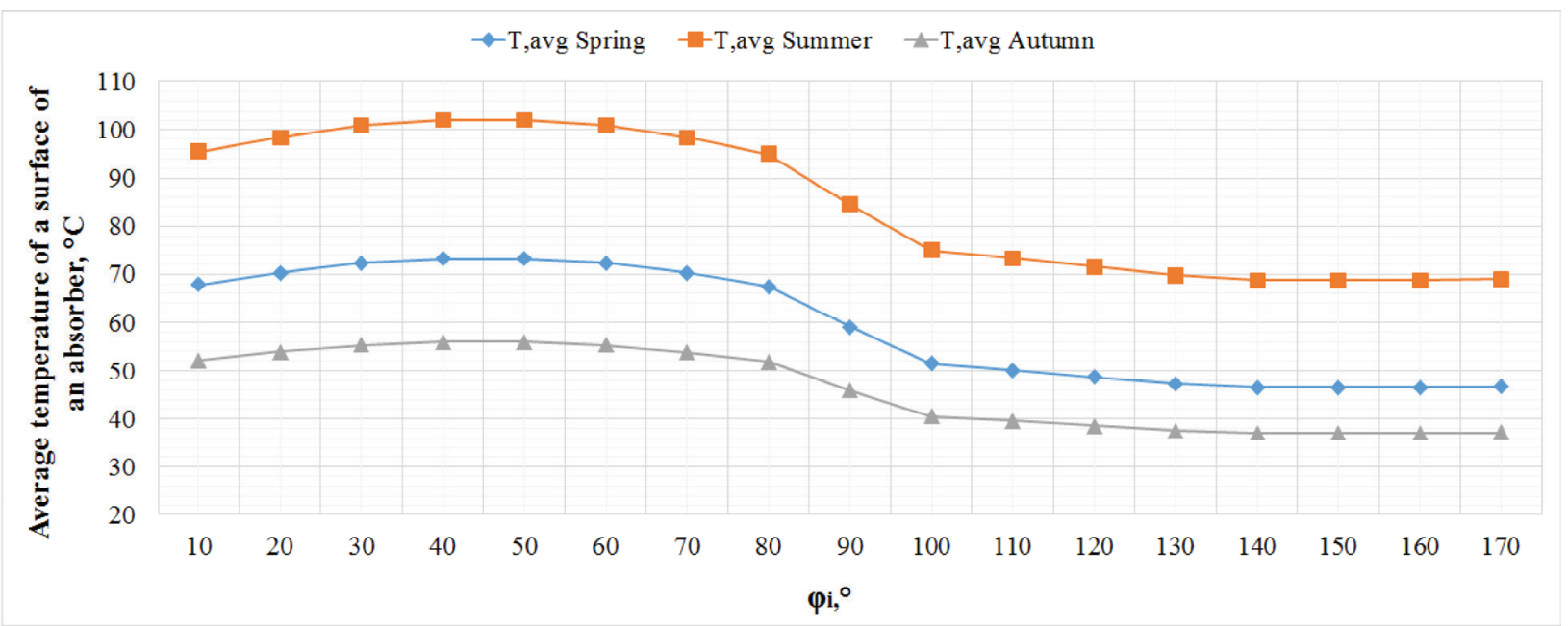

Fig. 5. the diagram of average temperature distribution of the absorber on a semi cylindrical surface of a segment depending on error angle $\varphi$ in case of sunlight impact at an angle $45^{\circ}$ 


\section{Analytical solution}

Thus, results of simulation modeling allow the authors to come to the conclusion that the authors' construction and the design of the inflatable collector provide heating of the coolant.

The study of various environmental factors affecting the efficiency of the collector is to be continued, the constructive decision is optimized, confectioning of polymer materials is executed by means of the software product.

\section{References}

1. O.A. Smirnova, I.V. Vashchinskaya, M.A Goncharova, Yu.E. Avetisyan, Innovations in Science: Sat. Art. by mater. LVI Intern. scientificpractical. Conf. No. 4 (53). Part II. - Novosibirsk: SibAK, 52-58 (2016)

2. O.A. Smirnova, M.A. Goncharova, Actual issues of technical sciences in modern conditions: Collection of scientific papers on the results of the international scientific and practical conference. St. Petersburg, 11/01/2016 - Innovation Center for the Development of Education and Science (2016)

3. A.N. Nikiforov, Optimization methods: Textbook. allowance (YURSTU (NPI), Novocherkassk, 2007)

4. GOST 28205-89 «Basic environmental testing procedures.Part 2.Tests. Guidance for solar radiation testing».

5. GOST P 51910-2002 «Research and testing strategy by accelerated metods of environmental conditions influence for industrial produets longevity and storege adility».

6. GOST 26883-86 «Exposure factors. Terms and definitions».

7. GOST 28202-89 «Basic environmental testing. Part 2. Tests. Test Sa: Simulated solar radiation at ground level».

8. O.A. Smirnova, M.A Goncharova, Yu.E. Avetisyan. Concept of complex assessment of operational indexes of an inflatable collector. Innovative researches: problems of introduction of results and direction of development. Perm, (2017)

9. V.V. Kostenyuk, A.V. Doroshenko, M.A. Glauberman, Khodililna tehnika te tehnologii, №8, 34-40 (2010)

10. A.N. Gorin, A.V. Doroshenko Solar energy (theory, development, practice), (Nord-Press Donetsk, 2008)

11. O.A. Smirnova, I.V. Vashchinskaya, Yu.E. Avetisyan, New science: current state and ways of development: International scientific periodical on the results of the International Scientific and Practical Conference, Part 2: RIC AMI, Sterlitamak (2015)

12. Yu.A. Bakhvalov, N.I. Gorbatenko, V.V. Grechikhin Inverse problems of electrical engineering: monograph (Izd-vo of the journal Izv. Universities. Electromechanics, Novocherkassk, 2014)

13. Encyclopedia of polymers 3 vol. V.A. MS Kabanov Akutin. Ed. Soviet Encyclopedia, 599-600 (1977)

14. O.A. Smirnova, I.V. Vashchinskaya, Yu.E. Avetisyan, International Scientific Journal, №8 7678, ISSN 2410-6070 (2015)

15. NASA Surface meteorology and Solar Energy https://eosweb.larc.nasa.gov/cgibin/sse/grid.cgi? \&num=221138\&lat $=47.709 \&$ subm $\mathrm{it}=\& \mathrm{hgt}=100 \& \mathrm{veg}=17 \&$ sitelev $=\&$ email $=\& p=$ grid i $\mathrm{d} \& \mathrm{p}=$ midday_dwn $\& \mathrm{p}=\mathrm{swv} d \mathrm{dwn} \& \mathrm{p}=\mathrm{sol}$ noon $\& \mathrm{p}=$ ret_psh0\&p=mnavail $1 \& \mathrm{p}=$ surplus $1 \& \mathrm{p}=\overline{\mathrm{T}} \mathrm{SKIN} \mathrm{M}$ $\mathrm{N} \& \mathrm{p}=$ toa_dwn\&step $=2 \&$ lon $=40.214$ 